\title{
Evaluation of Diversity and Traits Correlation in Spring Wheat Cultivars under Drought Stress
}

\author{
Mohammad Reza NAGHAVI ${ }^{1}$, Mahmoud TOORCHI ${ }^{2 *}$, Mohammad \\ MOGHADDAM ${ }^{2}$, Mohammad Reza SHAKIBA ${ }^{3}$ \\ IPayame Noor University, Department of Agriculture, PO BOX 19395-3697Tehran, Iran;mr_naghavi@ymail.com \\ ${ }^{2}$ University of Tabriz, Department of Plant BreedingandBiotechnology, Iran;mtoorchi@tabrizu.ac.ir (*correspondingauthor);moghaddamv@yahoo.com \\ ${ }^{3}$ University of Tabriz, Department of PlantEco-Physiology, Iran;mrshakiba@tabrizu.ac.ir
}

\begin{abstract}
In order to study of diversity and classify agro-morphological characters under normal irrigation and drought stress in spring wheat cultivars, 20 cultivars were evaluated in the research farm of University of Tabriz, Iran. According to the results, significant correlation was found between grain yield and number of spikes per plant, number of tiller per plant, number of fertile tillers, spike length, root length, root number, root volume, root diameter and root dry weight under both conditions. Moreover, 1,000 grain weight and plant dry weight had significant positive correlation with grain yield under drought stress. Factor analysis detected four and two factors which explained $96.77 \%$ and $90.59 \%$ of the total variation in normal irrigation and drought stress conditions, respectively. In drought stress condition the first factor justified $69.52 \%$ of total variation and was identified as yield factor. The second factor explained $21.07 \%$ of total variation and represented the biomass and plant height factor. Cluster analysis was based on the four and two factors obtained. According to the amount of factors for clusters obtained under drought stress, 'Kavir', 'Niknejhad', 'Moghan 3', 'Darya' and 'Marvdasht' were identified as the most drought tolerant cultivars. Other cluster was comprised of 'Bahar', 'Pishtaz, 'Bam', 'Sepahan', 'Sistan', 'Pars' and 'Sivand' and was named as the most sensitive under drought stress. Tolerant cultivars identified within the study can be used for direct culture or as genitors in breeding programs.
\end{abstract}

Keywords: agro-morphological trait, correlation, drought stress, factor analysis, wheat

\section{Introduction}

All the biotic and abiotic stress factors are reducing crop production nonetheless; drought stress is the most important factor limiting yield in agricultural systems in arid and semi-arid regions (Mollasedeghi et al., 2011). Wheat (Triticum aestivum L.), as the most important cereal crop, is cultivated throughout the major agro-climatic zones of the world. World's wheat production was about 704 million tons in 2011 (FAO, 2011). Iran is ranked as 14th in world wheat production. According to recent reports, wheat was cultivated on more than seven million ha and its total production was about 14.3 million tons in Iran, during 2010-2011 (FAO, 2011). The adaptability of wheat is an advantage, but drought, as the most important abiotic stress, is a major restriction to wheat and other agricultural production in arid and semi-arid regions (Delmer, 2005; Rajala et al., 2009). On the other hand, world demand for grain of wheat, as a stable food crop, is constantly increasing. Thus, it is an urgent need to develop new genotypes and cultivars with traits that could not only tolerate serious drought stress at various stages of growth, but can also produce higher grain yield under drought stress conditions (Talebi et al., 2009). Morphological and agronomic characters have a special role in determining the importance of each trait in regard to increasing yield, so these traits were used in breeding programs which led to introducing commercial varieties (Walton, 1972).

Different statistical techniques have been used in modelling crops' yield, including correlation, regression, path analysis, factor analysis, factor components and cluster analysis. Correlation coefficient is an important statistical procedure to evaluate breeding programs for high yield, as well as to examine direct and indirect contribution of the yield variables (Mohamed, 1999). Factor analysis suggested by Walton (1972) has been widely used to identify growth and plant characters related to wheat (Moghaddam et al., 1998; Mohamed, 1999). Therefore, a reasonable approach for categorizing the traits in the sample which contains the above variation necessitates the use of multivariable methods like factor analysis (Walton, 1972). This method basically reduces a large number of correlated variables to a small number of uncorrelated variables or factors. This method has been used to estimate the components of yield, to extract a subset of identical variables, to identify the basic concepts of multivariable data, to recognize applied and biological connections among the traits, to reduce a large number of correlative traits to a few number of factors and to explain the correlation among the variables (Bramel et al., 1984; Zakizadeh et al., 2010). 
350

Moghaddam et al. (1998) showed a negative correlation between plant height and grain yield. They attributed that to the lower number of grains/spike with the tallest wheat plants. Kumbhar et al. (1983) and Mohamed (1999) had shown that grain weight/spike, biological yield and number of spikes $/ \mathrm{m}^{-2}$ were closely related to grain yield $/ \mathrm{m}^{-2}$. The differential relations of yield components to grain yield may be attributed to environmental effects on plant growth (Asseng et al., 2002). Khayatnezhad et al. (2010) using factor analysis in his studies on durum wheat cultivars showed that the importance of factor coefficients characteristics of total and fertile tillers, main spike length, 1,000-seed weight and yield selected genotypes is desirable for dry conditions. Also, Gholamin et al. (2010) showed that the importance of factor coefficients characteristics of fertile tillers, grain weight, seeds' weight and harvest index selected genotypes is desirable for dry conditions. Walton (1971) used the factor analysis to identify growth and morphological traits relevant to yield in spring wheat and introduced four 666 factors which included yield components, morphological traits, spike length and the number of grain per plant.

Cluster analysis can be used to identify variables which can be classified into main groups and subgroups based on similarity and dissimilarity. This technique is useful for parental selection in breeding programs (El-Deeb and Mohamed, 1999) and crop modelling (Jaynes et al., 2003).

The objectives of this investigation were to evaluate the relations of different characters and to identify effective factors for yield improvement in spring wheat cultivars, thus grouping the tested cultivars according to the achieved factors under normal irrigation and drought stress conditions.

\section{Materials and Methods}

Twenty cultivars of spring wheat such as 'Mahdavi', 'Pishtaz', 'Bam', 'Sistan', 'Zargros', 'Marvdasht', 'Sepahan', 'Aflak', 'Arta', 'Arg,, 'Sivand', 'Pars', 'Bahar', 'BC Roshan', 'Kavir', 'Niknejhad', 'Darya', 'Morvarid', 'Roshan' and 'Moghan 3' were cultivated in a split plot basis of randomized complete block design with four replications, under two different conditions (normal irrigated and no irrigation after booting stage) in two years (2010-2012 and 2011-2012), at Research Farm of University of Tabriz, Iran (latitude $38.03^{\circ} \mathrm{N}$, longitude $46.17^{\circ} \mathrm{E}$, altitude $1,360 \mathrm{~m}$ above sea level. The climate is characterized by mean annual precipitation of $330 \mathrm{~mm}$ and mean annual temperature of $9.8^{\circ} \mathrm{C}$. All plots used were plastic tubes with $20 \mathrm{~cm}$ diameter and 1 meter length, full with mixed loam soil. Sowing was done by hand in plots with three plants per plot. All plots were irrigated at sowing time and subsequent irrigations depending on the treatment were carried out after booting stage for $\mathrm{I}_{1}$, as normal irrigation, and without irrigation for $\mathrm{I}_{2}$, as drought stress. Weeds were controlled by hand during crop growth and development.

Morphological and agronomic traits such as the plant height $(\mathrm{cm})(\mathrm{PH})$, plant dry weight (gr) (PDW), number of tillers per plant (NT), spike length $(\mathrm{cm})(\mathrm{SpL})$, number of fertile tillers per plant (NFT), number of roots (RN), length of root $(\mathrm{cm})(\mathrm{RL})$, volume of root $(\mathrm{ml})(\mathrm{RL})$, root dry weight (gr) (RDW), root diameter (mm) (RD), number of spikes per plant (NSp), grain per spike (NGSp), 1,000 grain weight (gr) (1000 GW) and grain yield (gr) (GY) were measured at the end of the growth stage. Finally, mean of data used for analysis and simple linear correlation coefficients were computed, then factor analysis on the base of major factors analysis and varimax rotations was done on the data. The factors which had a root bigger than one were selected and were used to form factorial coefficients matrix (Sharma and Choudhary, 1985; Talebi et al., 2009). Also Eigen values, percent variance, variance and cumulative percentage shared by each of the extracted factors were calculated. Finally, cluster analysis was performed according to values for all cultivars on the basis of selected factors. Data were statistically analyzed with SPSS software.

\section{Results and Discussion}

The results of analysis of variance (Table 1 ) showed high significant differences between cultivars $(\mathrm{P}<0.01)$ for all traits, except for root volume and root dry weight, which were significant in probability level $\mathrm{P}<0.05$. Also, differences between normal irrigation and drought stress were significant for all of traits under study. Results indicated that there was a high variation for all traits, which revealed the presence of genetic diversity for these attributes. Therefore, these traits have good potential for identifying the most tolerant and most sensitive cultivars for using as genitors in crosses and create genetically variation or selecting some for direct culture.

\section{Correlation analysis}

According to the results of the correlation, significant correlations were found between grain yield and number of spikes per plant, number of tillers per plant, number of fertile tillers, spike length, root length, roots number, root volume, root diameter and root dry weight under both conditions (Tables 2 and 3). Moreover, 1,000 grain weight and plant dry weight had significant positive correlation with grain yield under drought stress (Table 3).Whereas correlation between 1,000 grain weight and number of grain per spike was negative, with significant differences among the two conditions in the experiment. Correlation analysis showed that root traits were positive and significantly correlated together under the two conditions. Further, the number of tillers with the number of fertile tillers and number of spikes per plant had significant positive correlation under normal irrigation and drought stress. Plant height was positively correlated with plant dry weight under both conditions. Also spike length showed positive and significant correlation with the number of grain per spike under normal irrigation and drought stress.

The analysis of correlation among different traits with grain yield can indicate the relative importance of these traits and their merits as selection criteria (Agrama, 1996). Various studies showed that grain yield of wheat was significantly correlated with 1,000 grain weight, the number of fertile tillers or spikes per plant and the number of spikelets per spike (Mohiuddin and Cory, 1980; Shanahan et al., 1985). Moghaddam et al. (1998) reported that yield, 1,000 grain weight and the number of spikes per plant were correlated. In most of the previous studies, similar findings have been reported between yield and related characters such as the number of spikes, number of spikelet and 1,000 grain weight (Sharma and Rao, 1989; Subhani and Khaliq, 1994). In the studies conducted by Sinha and Sharma (1979) and Belay et al. (1993), yield was positively correlated with yield components, with either positive or negative correlation between yield and plant height.

\section{Factor analysis}

Studying the correlation coefficient among different characters makes it possible to decide more precisely about indirect selection indices and removing ineffective characters 
Table 1. Analysis of variance for yield and other traits in spring wheat cultivars under different irrigation treatments

\begin{tabular}{|c|c|c|c|c|c|c|c|}
\hline \multirow{2}{*}{ Source of variation } & \multicolumn{7}{|c|}{ Mean of squares } \\
\hline & $\mathrm{PH}$ & PDW & $\mathrm{RN}$ & $\mathrm{RL}$ & RV & RDW & $\mathrm{RD}$ \\
\hline Year $(\mathrm{Y})$ & $722.402^{* *}$ & $37.813^{* *}$ & 70.313 & $257.045^{* *}$ & $135.07^{* *}$ & 1.307 & $2.297^{* *}$ \\
\hline Replication (Y) & .303 & .002 & 26.079 & .304 & .127 & .213 & .047 \\
\hline Stress (S) & $7,566.05^{* *}$ & $250.632^{* *}$ & $4,712.45^{* *}$ & $3,476.885^{* *}$ & $2,443.708^{* *}$ & $202.585^{* *}$ & $47.625^{* *}$ \\
\hline $\mathrm{Y} \times \mathrm{S}$ & .002 & .113 & .05 & .004 & .000031 & .001 & .00007 \\
\hline Error & .561 & .009 & 6.317 & .004 & .122 & .047 & .046 \\
\hline Genotype (G) & $86.855^{* *}$ & $4.274^{* *}$ & $124.931^{* *}$ & $85.582^{* *}$ & $22.084^{*}$ & $1.693^{*}$ & $.561^{* *}$ \\
\hline$G \times Y$ & 42.598 & 1.838 & 26.576 & 15.03 & 3.457 & .415 & .064 \\
\hline $\mathrm{G} \times \mathrm{S}$ & 26.866 & 1.91 & 24.437 & 13.463 & 6.059 & .675 & .171 \\
\hline $\mathrm{G} \times \mathrm{S} \times \mathrm{Y}$ & 35.86 & 1.756 & 6.155 & 4.151 & 2.147 & .147 & .046 \\
\hline Error & 40.945 & 1.916 & 23.501 & 14.374 & 11.553 & 1.008 & .259 \\
\hline $\begin{array}{l}\frac{C V(\%)}{\text { PH- Plant Height, PD }} \\
\text { Length, NT Number o } \\
\text { Weight, GY- Grain Yiel }\end{array}$ & $\begin{array}{l}\frac{12.57}{\text { Plant Dry Wei }} \\
\text { llers per Plant, } \\
\text { and }{ }^{* *} \text { were sign }\end{array}$ & $\begin{array}{l}\frac{9.61}{\text { - Root Nun }} \\
\text { Jumber Fer } \\
\text { at } 5 \% \text { and } 1\end{array}$ & $\begin{array}{l}\frac{23.19}{2-\text { Root Len }} \\
\text { rs, NSp- N } \\
\text { bility levels }\end{array}$ & 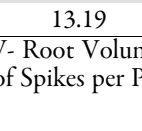 & $\begin{array}{c}\frac{21.01}{\text { DW- Root Dry }} \\
\text { NGSp- Number }\end{array}$ & $\begin{array}{c}34.90 \\
\text { hht, RD- Root I } \\
\text { in per Spike, } 10\end{array}$ & 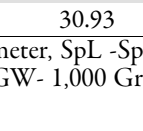 \\
\hline \multicolumn{8}{|l|}{ Table 1. Continued } \\
\hline \multirow{2}{*}{ Source of variation } & \multicolumn{7}{|c|}{ Mean of Squares } \\
\hline & $\mathrm{SpL}$ & NT & NFT & NSp & NGSp & $1000 \mathrm{GW}$ & GY \\
\hline Year $(\mathrm{Y})$ & $217.47^{* *}$ & $109.278^{* *}$ & $105.8^{* *}$ & $105.8^{* *}$ & $257.403^{* *}$ & $252.938^{* *}$ & $345.975^{* *}$ \\
\hline Replication (Y) & .055 & .52 & .465 & .315 & $40.461^{* *}$ & 22.272 & .851 \\
\hline Stress $(\mathrm{S})$ & $349.448^{* *}$ & $444.153^{* *}$ & $437.113^{* *}$ & $437.113^{* *}$ & $747.253^{* *}$ & $4,334.304^{* *}$ & $2,146.42^{* *}$ \\
\hline $\mathrm{Y} \times \mathrm{S}$ & .000125 & .078 & .0000001 & .0000001 & $166.753^{* *}$ & .053 & .502 \\
\hline Error & .022 & $4.249^{* *}$ & $4.415^{* *}$ & $4.131^{* *}$ & $47.186^{* *}$ & $26.42^{*}$ & $6.115^{* *}$ \\
\hline Genotype (G) & $10.123^{* *}$ & $13.64^{* *}$ & $13.835^{* *}$ & $14.527^{* *}$ & $108.495^{* *}$ & $64.452^{* *}$ & $17.112^{* *}$ \\
\hline $\mathrm{G} \times \mathrm{Y}$ & $1.447^{*}$ & 1.153 & 1.03 & 1.03 & 13.416 & 13.576 & 2.006 \\
\hline $\mathrm{G} \times \mathrm{S}$ & .436 & 1.449 & 1.382 & 1.422 & $60.279^{* *}$ & $34.054^{* *}$ & $3.9^{*}$ \\
\hline$G \times S \times Y$ & .246 & 1.058 & .862 & .862 & $23.161^{*}$ & 10.596 & 1.388 \\
\hline Error & .876 & 1.099 & 1.119 & 1.183 & 12.583 & 11.537 & 1.999 \\
\hline CV (\%) & 9.97 & 14.05 & 16.45 & 17.01 & 10.91 & 9.08 & 17.83 \\
\hline
\end{tabular}

Table 2. Correlation analysis between the studied traits with grain yield under normal irrigation

\begin{tabular}{|c|c|c|c|c|c|c|c|c|c|c|c|c|c|c|}
\hline & PH & PDW & $\mathrm{RN}$ & $\mathrm{RL}$ & RV & RDW & $\mathrm{RD}$ & SpL & NT & NFT & NSp & NGSp & $1000 \mathrm{GW}$ & GY \\
\hline PDW & $.966^{* *}$ & 1 & & & & & & & & & & & & \\
\hline $\mathrm{RN}$ & -0.291 & -0.316 & 1 & & & & & & & & & & & \\
\hline RL & -0.229 & -0.25 & $.981^{* *}$ & 1 & & & & & & & & & & \\
\hline $\mathrm{RV}$ & -0.155 & -0.22 & $.907^{* *}$ & $.896^{* *}$ & 1 & & & & & & & & & \\
\hline RDW & -0.173 & -0.248 & $.900^{* *}$ & $.880^{* *}$ & $.956^{* *}$ & 1 & & & & & & & & \\
\hline RD & -0.031 & -0.113 & $.856^{* *}$ & $.865^{* *}$ & $.960^{* *}$ & $.902^{* *}$ & 1 & & & & & & & \\
\hline SpL & -0.151 & -0.132 & $.894^{* *}$ & $.888^{* *}$ & $.815^{* *}$ & $.786^{* *}$ & $.729^{* *}$ & 1 & & & & & & \\
\hline NT & -0.122 & -0.112 & $.822^{* *}$ & $.855^{* *}$ & $.630^{* *}$ & $.664^{* *}$ & $.648^{* *}$ & $.811^{* *}$ & 1 & & & & & \\
\hline NFT & -0.102 & -0.087 & $.785^{* *}$ & $.832^{* *}$ & $.592^{* *}$ & $.610^{* *}$ & $.616^{* *}$ & $.799 * *$ & $.989^{* *}$ & 1 & & & & \\
\hline NSp & -0.073 & -0.042 & $.766^{* *}$ & $.819^{* *}$ & $.573^{* *}$ & $.582^{* *}$ & $.600^{* *}$ & $.794^{* *}$ & $.984^{* *}$ & $.993^{* *}$ & 1 & & & \\
\hline NGSp & 0.203 & 0.178 & -0.405 & -0.331 & -0.265 & -0.292 & -0.165 & $.532^{*}$ & -0.365 & -0.379 & -0.336 & 1 & & \\
\hline $1000 \mathrm{GW}$ & -0.393 & -0.338 & 0.4 & 0.335 & 0.25 & 0.241 & 0.147 & $.511^{*}$ & 0.351 & 0.374 & 0.352 & $-.916^{* *}$ & 1 & \\
\hline GY & 0.398 & -0.123 & $.756^{* *}$ & $.806^{* *}$ & $.564^{* *}$ & $.557^{*}$ & $.580^{* *}$ & $.788^{* *}$ & $.957^{* *}$ & $.968^{* *}$ & $.983^{* *}$ & -0.322 & 0.41 & 1 \\
\hline
\end{tabular}

PH- Plant Height, PDW- Plant Dry Weight, RN- Root Number, RL- Root Length, RV- Root Volume, RDW- Root Dry Weight, RD- Root Diameter, SpL -Spike Length, NT Number of Tillers per Plant, NFT- Number Fertile Tillers, NSp- Number of Spikes per Plant, NGSp- Number Grain per Spike, 1000 GW- 1,000 Grain Weight, GY- Grain Yield; * and ${ }^{* *}$ were significant at $5 \%$ and $1 \%$ probability levels

Table 3. Correlation analysis between the studied traits with grain yield under drought stress

\begin{tabular}{|c|c|c|c|c|c|c|c|c|c|c|c|c|c|c|}
\hline & $\mathrm{PH}$ & PDW & $\mathrm{RN}$ & RL & RV & RDW & $\mathrm{RD}$ & SpL & NT & NFT & NSp & NGSp & $1000 \mathrm{GW}$ & GY \\
\hline PDW & $.960^{* *}$ & 1 & & & & & & & & & & & & \\
\hline $\mathrm{RN}$ & 0.138 & 0.314 & 1 & & & & & & & & & & & \\
\hline RL & 0.345 & $.515^{*}$ & $.897^{* *}$ & 1 & & & & & & & & & & \\
\hline $\mathrm{RV}$ & 0.355 & $.526^{*}$ & $.849^{* * *}$ & $.935^{* *}$ & 1 & & & & & & & & & \\
\hline RDW & 0.39 & $.558^{*}$ & $.870^{* *}$ & $.957^{* *}$ & $.962^{* *}$ & 1 & & & & & & & & \\
\hline $\mathrm{RD}$ & 0.289 & $.462^{*}$ & $.852^{* *}$ & $.920^{* *}$ & $.983^{* *}$ & $.929^{* *}$ & 1 & & & & & & & \\
\hline SpL & 0.384 & $.553^{*}$ & $.843^{* *}$ & $.952^{* *}$ & $.957^{* *}$ & $.969^{* *}$ & .948* & 1 & & & & & & \\
\hline NT & 0.356 & $.516^{*}$ & $.782^{* *}$ & $.878^{* *}$ & $.933^{* *}$ & $.885^{* *}$ & $.925^{* *}$ & $.932^{* *}$ & 1 & & & & & \\
\hline NFT & 0.383 & $.536^{*}$ & $.766^{* *}$ & $.858^{* *}$ & $.923^{* *}$ & $.868^{* *}$ & $.913^{* *}$ & $.915^{* *}$ & $.996 *$ & 1 & & & & \\
\hline NSp & 0.388 & $.532^{*}$ & $.764^{* *}$ & $.835^{* *}$ & $.901^{* *}$ & $.84 \mathrm{f}^{* *}$ & $.885^{* *}$ & $.890^{* *}$ & $.986^{* *}$ & $.993^{* *}$ & 1 & & & \\
\hline NGSp & $-460^{*}$ & $-.582^{* *}$ & $-.734^{* *}$ & $-849^{* *}$ & $-864^{* *}$ & $-853^{* *}$ & $-814^{* *}$ & $.878^{* *}$ & $-880^{* *}$ & $-877^{* *}$ & $-893^{* *}$ & 1 & & \\
\hline $1000 \mathrm{GW}$ & $.587^{* *}$ & $.704^{* *}$ & $.646^{* *}$ & $.771^{* *}$ & $.823^{* *}$ & $.763^{* *}$ & $.801^{* *}$ & $.806^{* *}$ & $.777^{* *}$ & $.769^{* *}$ & $.768^{* *}$ & $-843^{* *}$ & 1 & \\
\hline GY & 0.413 & $.565^{* *}$ & $.727^{* *}$ & $.762^{* *}$ & $.860^{* *}$ & $.779 *$ & $.861^{* *}$ & $.822^{* *}$ & $.927^{* *}$ & $.939^{* *}$ & $.938^{* *}$ & $-803^{* *}$ & $.821^{* *}$ & 1 \\
\hline
\end{tabular}

PH- Plant Height, PDW- Plant Dry Weight, RN- Root Number, RL- Root Length, RV- Root Volume, RDW- Root Dry Weight, RD- Root Diameter, SpL-Spike Length, NT Number of Tillers per Plant, NFT- Number Fertile Tillers, NSp- Number of Spikes per Plant, NGSp- Number Grain per Spike, 1000 GW- 1,000 Grain

Weight, GY- Grain Yield; ${ }^{*}$ and ${ }^{* *}$ were significant at $5 \%$ and $1 \%$ probability levels 
Table 4. Factor analysis for agro-morphological traits in spring wheat cultivars under normal irrigation

\begin{tabular}{|c|c|c|c|c|c|}
\hline Traits & 1 & 2 & 3 & 4 & Communalities \\
\hline $\mathrm{PH}$ & -0.044 & -0.059 & -0.149 & 0.980 & 0.987 \\
\hline PDW & -0.139 & 0.002 & -0.102 & 0.977 & 0.984 \\
\hline $\mathrm{RN}$ & 0.783 & 0.522 & 0.205 & -0.198 & 0.967 \\
\hline RL & 0.759 & 0.597 & 0.126 & -0.143 & 0.969 \\
\hline RV & 0.950 & 0.264 & 0.097 & -0.082 & 0.989 \\
\hline RDW & 0.918 & 0.284 & 0.102 & -0.108 & 0.945 \\
\hline $\mathrm{RD}$ & 0.916 & 0.315 & -0.012 & 0.021 & 0.938 \\
\hline $\mathrm{SpL}$ & 0.653 & 0.571 & 0.381 & -0.016 & 0.897 \\
\hline NT & 0.407 & 0.890 & 0.148 & -0.035 & 0.980 \\
\hline NFT & 0.354 & 0.912 & 0.172 & -0.013 & 0.987 \\
\hline NSp & 0.330 & 0.932 & 0.142 & 0.018 & 0.998 \\
\hline NGSp & -0.141 & -0.163 & -0.960 & 0.051 & 0.970 \\
\hline $1000 \mathrm{GW}$ & 0.078 & 0.213 & 0.922 & -0.245 & 0.962 \\
\hline GY & 0.303 & 0.924 & 0.156 & -0.073 & 0.976 \\
\hline Eigen values & 4.74 & 4.63 & 2.12 & 2.06 & \\
\hline Proportional variance & 33.84 & 33.04 & 15.16 & 14.73 & \\
\hline Cumulative variance & 33.84 & 66.88 & 82.04 & 96.77 & \\
\hline
\end{tabular}

PH- Plant Height, PDW- Plant Dry Weight, RN- Root Number, RL- Root Length, RV- Root Volume, RDW- Root Dry Weight, RD- Root Diameter, SpL -Spike Length, NT Number of Tillers per Plant, NFT- Number Fertile Tillers, NSp- Number of Spikes per Plant, NGSp- Number Grain per Spike, 1000 GW- 1,000 Grain Weight, GY- Grain Yield

Factor 1- root factor, Factor 2- growth and yield factor, Factor 3- grain factor, Factor 4- biomass and plant height factor

Table 5. Factor analysis for agro-morphological traits in spring wheat cultivars under drought stress

\begin{tabular}{|c|c|c|c|}
\hline Traits & 1 & 2 & Communalities \\
\hline $\mathrm{PH}$ & 0.115 & 0.982 & 0.977 \\
\hline PDW & 0.304 & 0.938 & 0.973 \\
\hline $\mathrm{RN}$ & 0.908 & 0.005 & 0.824 \\
\hline RL & 0.921 & 0.228 & 0.900 \\
\hline RV & 0.948 & 0.251 & 0.961 \\
\hline RDW & 0.914 & 0.273 & 0.910 \\
\hline $\mathrm{RD}$ & 0.954 & 0.181 & 0.944 \\
\hline SpL & 0.932 & 0.278 & 0.947 \\
\hline NT & 0.936 & 0.260 & 0.943 \\
\hline NFT & 0.919 & 0.288 & 0.928 \\
\hline $\mathrm{NSp}$ & 0.905 & 0.295 & 0.906 \\
\hline NGSp & -0.831 & -0.386 & 0.839 \\
\hline $1000 \mathrm{GW}$ & 0.712 & 0.555 & 0.814 \\
\hline GY & 0.839 & 0.335 & 0.817 \\
\hline Eigen values & 9.73 & 2.95 & \\
\hline $\begin{array}{c}\text { Proportional } \\
\text { variance }\end{array}$ & 69.52 & 21.07 & \\
\hline $\begin{array}{c}\text { Cumulative } \\
\text { variance }\end{array}$ & 69.52 & 90.59 & \\
\hline
\end{tabular}

PH- Plant Height, PDW- Plant Dry Weight, RN- Root Number, RL- Root Length, RV- Root Volume, RDW- Root Dry Weight, RD- Root Diameter, SpL Spike Length, NT Number of Tillers per Plant, NFT- Number Fertile Tillers, NSp- Number of Spikes per Plant, NGSp- Number Grain per Spike, 1000 GW1,000 Grain Weight, GY-Grain Yield

Factor 1-yield factor, Factor 2- biomass and plant height factor

from the selection criteria. Further, since coefficients of correlation by themselves do not provide thorough information about the relations between different traits, and given the various advantages of multivariate statistical analyses for deep understanding of data structure, factor analysis was used in the current study. By means of varimax rotation which maximizes the variance among the factors, those which justify more percentage of variations among the characters have had more importance and must be used for further study. Thus, the effective characters on each factor are identified and the factors are named according to the most effective characters (Harman, 1976; Sharma and Choudhary, 1985; Talebi et al., 2009).
For the current study, within factor analysis by means of major factors and on the base of specific numbers higher than 1 , four factors were identified under normal irrigation and two factors were identified under drought stress (no irrigation) and they all together justify $96.77 \%$ and $90.59 \%$ of the existent variation among the characters, respectively (Table 4 and 5). Under irrigation condition, the first factor which made $33.84 \%$ of the total variation was composed of the root length, roots number, root volume, root diameter and root dry weight. Therefore this factor was named as root factor. Factor 2, which accounted $33.04 \%$ of the total variation was composed of grain yield, number of tillers per plant, number of fertile tillers and number of spikes per plant and thus this factor was called as growth and yield factor. Factor 3, which accounted $15.16 \%$ of the total variation, included the number of grain per spike and 1,000 grain weight. Because these traits were related to grain, the third factor was named as grain factor. Factor 4, which accounted $14.73 \%$ of the total variation, was composed of plant height and plant dry weight and thus this factor was called as biomass and plant height factor.

On the other hand, under drought stress condition the first factor justified $69.52 \%$ of total variation and included the coefficient factors for all of traits except of plant height and plant dry weight. Therefore, this factor was identified as yield and effective traits on yield factor. Finally, the second factor was composed of plant height and plant dry weight and explained $21.07 \%$ of total variation. Thus this factor was called as biomass and plant height factor.

These coefficients showed that cultivars with higher values of these factors also had the highest values for traits related to their names. In general, factor analysis shows which yield components were associated with which morphological and agronomical characters. Gupta et al. (1999) studied 17 traits of 40 lines of advanced generations of wheat as well as 11 controls on the basis of a randomized complete block design and factor analysis; the researchers reduced these grain quality and yieldrelated traits to 5 major factors of maturity, spike attributes, grain attributes, protein quality and tillering (Gupta et al., 1999). In another study on bread wheat cultivars, Dawari and Luthra (1991) revealed that harvest index, grain number per 
Table 6. The average of traits for achieved groups from cluster analysis, based on factor analysis in 20 spring wheat cultivars under normal irrigation

\begin{tabular}{ccccc}
\hline Cluster & Factor 1 & Factor 2 & Factor 3 & Factor 4 \\
\hline 1 & 60.213 & 65.660 & 12.089 & 52.118 \\
2 & 53.808 & 56.971 & 7.679 & 54.928 \\
3 & 69.857 & 75.410 & 19.430 & 47.721 \\
\hline Factor 1- root factor, Factor 2- growth and yield factor, Factor 3- grain factor,
\end{tabular}

Factor 4- biomass and plant height factor

Table 7. The average of traits for achieved groups from cluster analysis, based on factor analysis in 20 spring wheat cultivars under drought stress

\begin{tabular}{ccc}
\hline Cluster & Factor 1 & Factor 2 \\
\hline 1 & 110.251 & 88.850 \\
2 & 94.109 & 78.401 \\
3 & 134.267 & 96.052 \\
\hline
\end{tabular}

Factor 1- yield factor, Factor 2- biomass and plant height factor

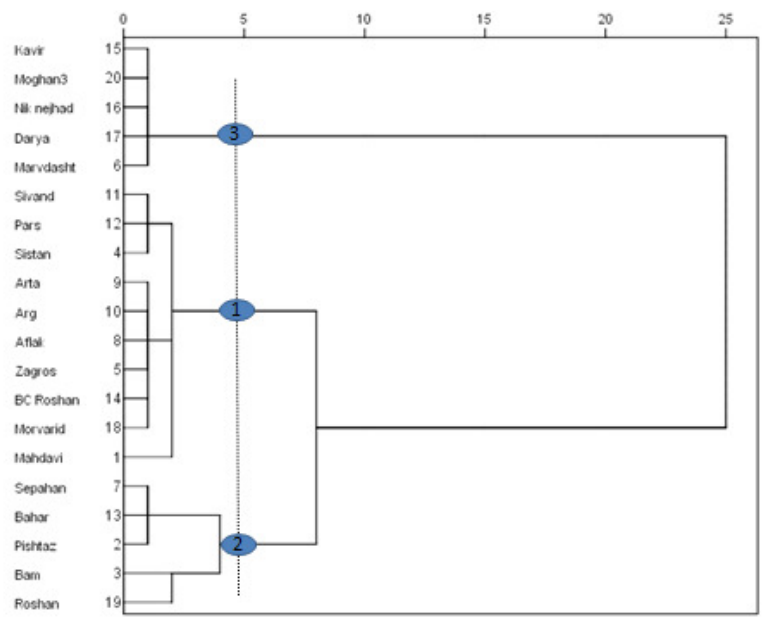

Fig. 1. Dendrogram obtained based on the factors obtained under normal irrigation

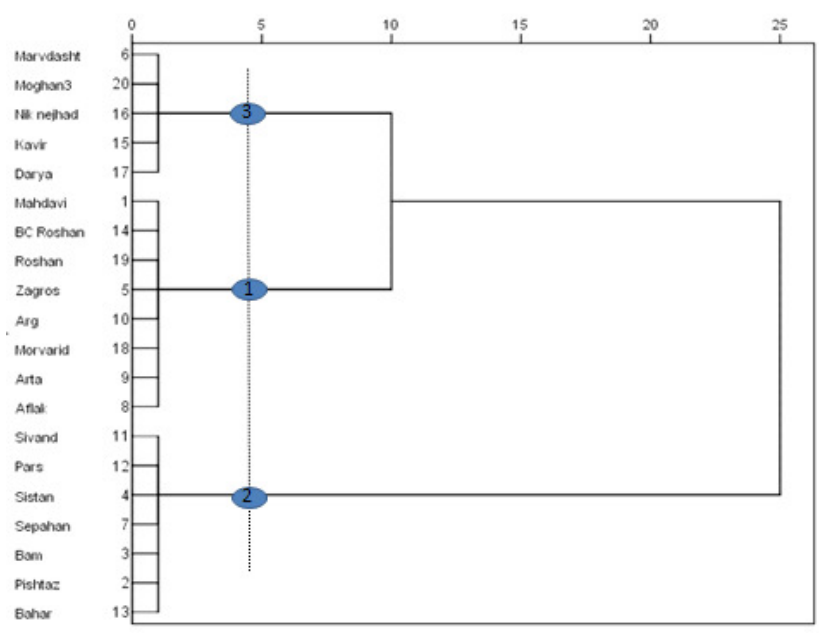

Fig. 2. Dendrogram obtained based on the factors under drought stress

spike and spike length were the main yield components and that a selection based on them could improve the yield. Also, Golparvar et al. (2002) reported plant height as the forth factor, Mohammadi et al. (2002) reported it as the fifth factor and
Damania and Jackson (1986) reported it as the third factor, thus having a major significance in selection of productive genotypes.

\section{Cluster analysis based on extracted factors}

According to the importance of all traits for increasing grain yield and regarding the correlation between traits that was effective into different factors, it was possible to group cultivars on the basis of all factors under normal irrigation (Fig. 1) and drought stress (Fig. 2). Also, according to the amount of factors for each group it can be concluded that cultivars may be classified within the drought tolerant or sensitive groups (Tables 6 and 7).

Cluster analysis based on the four and two factors grouped the studied cultivars into three groups under normal irrigation and drought stress respectively (Figs. 1 and 2). Under normal irrigation (Fig. 1), in the first cluster, five cultivars such as 'Kavir', 'Darya', 'Niknejhad', 'Moghan 3' and 'Marvdasht' were classified. Cultivars in this cluster had the highest rate with respect to first, second and third factors and the lowest value for the fourth factor. On this basis, it can be concluded that these cultivars have high yield and component yield, with best of root traits, whereas this group has the lowest height and the lowest dry weight. The third group comprised of 5 cultivars such as 'Sepahan', 'Bahar', 'Pishtaz', 'Bam' and 'Roshan'. Cultivars in this cluster had the lowest values for first to third factors and the highest values for the fourth factor. Thus, these cultivars had the lowest grain yield and component yield and the lowest values for root traits as well as the highest plant height and plant dry weight. The rest of the studied cultivars settle between these two clusters according to the values of the four factors.

On the other hands, under drought stress condition, the third cluster in the dendogram (Fig. 2) had 5 cultivars, similar to normal irrigation group, such as 'Kavir', 'Niknejhad', 'Moghan 3', 'Darya' and 'Marvdasht'. These cultivars were the most drought tolerant ones (Table 7). Thus it can be concluded that these cultivars can be used in breeding programs for increasing grain yield. The third cluster comprised of 'Bahar', 'Pishtaz, 'Bam', 'Sepahan', 'Sistan', 'Pars' and 'Sivand'; these cultivars, according to the amounts of factors obtained, were named as the most sensitive under drought stress. The rest of the cultivars under study had middle values for the established factors (Table 7).

\section{Conclusions}

The study has shown the existence of considerable genetic variation among the cultivars considered, that may help for further selection and breeding. Genitors may be selected from those clusters which had significant genetic distance in order to obtain valuable genetic recombination and transgressed segregation in the subsequent generations. Also, it might be suggested that the tolerant cultivars emphasized in the experiment are appropriate for direct culture in semidry regions.

\section{References}

Agrama HAS (1996). Sequential path analysis of grain yield and its components in maize. Plant Breeding 115(5):343-346.

Asseng S, Turner NC, Ray JD, Keating BA (2002). Assimilation analysis that predicts the influence of physiological traits on the potential yield of wheat. European Journal of Agronomy 17(2):123-141. 
354

Belay G, Tesemma, T, Becker HC, Merker A (1993). Variation and interrelationships of agronomic traits in Ethiopian tetraploid wheat landraces. Euphytica 71:181-188.

Bramel PJ, Hinnz PN, Green DE, Shibles RM (1984).Use of principal factor analysis in the study of three stem termination types of soybean. Euphytica 33:387-400.

Damania AB, Jackson MT (1986). An application of factor analysis to morphological data of wheat and barley landraces from the Bheri River Valley, Nepal. Rachis 5:25-30.

Dawari NH, Luthra OP (1991). Character association studies under high and low environments in wheat (Triticum aestivum $\mathrm{L}$.). Indian J Agric Res 25:68-72.

Delmer DP (2005). Agriculture in the developing world: connecting innovations in plant research to downstream applications. Academy of Sciences of the United States of America 102(44): 15739-15746.

Gholamin R, Zaeifizadeh M, Khayatnezhad M (2010). Factor analysis for performance and other characteristics in durum wheat under drought stress and without stress. Middle-East Journal of Scientific Research 6(6):599-603.

Golparvar AR, Ghannadha MR, Zalli AA, Ahmadi A (2002). Evaluation of some morphological traits as selection criteria for improvement of bread wheat. Iranian J Agric Sci 4(3):202-207.

Gupta AK, Mittal RK, Ziauddin A (1999). Association and factor analysis in spring wheat. Annals of Agricultural Research 20:481485.

Harman HH (1976). Modern factor analysis. 3th ed. University of Chicago Press.

Jaynes DB, Kaspar TC, Colvin TS, James DE (2003). Cluster analysis of Spatiotemporal corn yield patterns in an Iowa Field. Agronomy Journal 95(3):574-586.

Khayatnezhad M, Zaefizadeh M, Gholamin R, Jamaati-e-Somarin S, Zabihi-e-Mahmoodabad R (2010). Study of morphological traits of wheat cultivars through factor analysis. American-Eurasian J Agric \& Environ Sci 9(5):460-464.

Kumbhar MB, Larik AS, Hafiz HM, Rind MJ (1983). Wheat Information Services. Crop Science 57:42-45.

Moghaddam M, Ehdaie B, Waines JG (1998). Genetic variation for interrelationships among agronomic traits in landraces of bread wheat from Southwestern Iran. Journal of Genetics and Breeding 52:73-82.
Mohamed NA (1999). Some statistical procedures for evaluation of the relative contribution for yield components in wheat. Zagazig Journal of Agricultural Research 26(2):281-290.

Mohammadi M, Ghanadha MR, Taleei A (2002). Study of the genetic variation within Iranian local bread wheat lines using multivariate techniques. Seed and Plant Improvment Journal 18(3):328-347.

Mohiuddin SH, Cory LI (1980). Flag leaf and peduncle area duration in relation to winter wheat grain yield. Agronomy Journal 72:299-301.

Mollasadeghi V, Valizadeh M, Shahryari RA, Imani A (2011). Evaluation of end drought tolerance of 12 wheat genotypes by stress in dices. Middle-East Journal of Scientific Research 7(2):241-247.

Rajala A, Hakala K, Makela P, Muurinen S, Peltonen-Sainio P (2009). Spring wheat response to timing of water deficit through sink and grain filling capacity. Field Crops Research 114(2):263-271.

Shanahan JF, Donnelly KJ, Smith DH, Sminka DE (1985). Shoot developmental properties associated with grain yield in winter wheat. Crop Science 25:770-775.

Sharma SC, Rao SRG (1989). Genetic variability, association among metric traits and path coefficient analysis in Triticale. Ann Agric Res 10(2):145-152.

Sharma SK, Choudhary SK (1985). Factor analysis of berry and its seed characteristics in potato. Genetica Iberica 37:77-82.

Sinha GCP, Sharma NN (1979). Correlation regression and path analysis studies in wheat varieties. Indian Journal of Agronomy 25:225-229.

Subhani GM, Khaliq I (1994). Path coefficient analysis in wheat. Pakistan Journal of Scientific and Industrial Research 37(11):474476.

Tadesse W, Bekele E (2001). Factor analysis of yield in grass pea (Lathyrus sativus L.). Lathyrus Lathyrism Newsletter 2:416-421.

Talebi R, Fayaz F, Naji AM (2009). Effective selection criteria for assessing drought stress tolerance in durum wheat (Triticum durum Desf). General and Applied Plant Physiology 35(1-2):64-74.

Walton PD (1971). The use of factor analysis in determining characters for yield selection in wheat. Euphytica 20:416-421.

Walton PD (1972). Factor analysis of yield in spring wheat (Triticum aestivum). Crop Science 12:731-733.

Zakizadeh M, Esmaeilzadeh M, Kahrizi D (2010). Study on genetic variation and relationship between plant characteristics and yield in long spike bread wheat (Triticum aestivum L.) genotypes using multivariate analysis. Iranian Journal of Crop Sciences 12(1):18-30. 